\title{
Post Occupancy Monitoring: An introduction
}

\author{
Tia Kansara \\ Energy Institute, University College London \\ 14 Upper Woburn Place, London \\ WC1H 0NN, UK \\ E-mail: tia.kansara.10@ucl.ac.uk
}

Received: July 30, 2013 Accepted: August 19, 2013

doi:10.5296/emsd.v2i2.4215 URL: http://dx.doi.org/10.5296/emsd.v2i2.4215

\begin{abstract}
This paper introduces the method of Post Occupancy Monitoring as an evolution from Post Occupancy Evaluation of the built environment. The technique depends on the qualitative and quantitative aspirations of the stakeholders to apply methods resulting in closing the feedback loop of the built environment. Previous attempts are discussed such as the Royal Institute of British Architects (RIBA) Plan of Work for architects as well as the Soft Landings approach for handing over the building once commissioned. A gap in literature exists in the manner of continuously analyzing a building once it is handed over. Suitable incentives must be given to each of the stakeholders to participate in the process and learn from past initiatives. The paper suggests the need for energy monitoring, thermal comfort analysis and documenting user satisfaction as a basis for all existing building rating systems.
\end{abstract}

Keywords: Post Occupancy Evaluation, POE, POM, Building Performance Evaluation, Thermal Comfort, BEMS

\section{Introduction}

The effect of the environment on human attitudes is thoroughly researched [Fisk 2000, Hedge and Wilson 1987, Kats 2003, CIBSE 1999]. The measurement techniques for those in the built environment are, however, less well defined and are very difficult to implement [Pegg, 2007]. POE can evaluate any building (later we will see how a continuous monitoring can be just as beneficial if not more). Once constructed, however, seldom do buildings live up to their design features [Leaman, 2007: p.22]. Surprisingly after closer scrutiny, green buildings, which in theory would perform better, may not match their intended energy efficiency. The input of Post Occupancy Monitoring into the building industry can make significant improvements as the knowledge gap between stakeholders is closed. 


\section{MInstitute ${ }_{\text {Math }}^{\text {Macrothink }}$}

Furthermore, user satisfaction of the building can give detailed information about the characteristics of the building, which architects, engineers and facilities management could miss. This information, if gathered and analysed well, may fill the gap between users' knowledge of buildings and the design of future buildings.

The slow speed at which this information reaches the right people at present is shocking. To understand how best to capture this information around the world and apply it is the role that POE plays. New Media could provide platforms to manage this shift where users play a more participatory role in future build.

POE commences with one fundamental question, how does one introduce the much-needed development and upgrade of buildings successfully? Adrian Leaman and Bill Bordass have tirelessly worked on discovering the strategy of building awareness so that they do not fall below the good intentions secured at concept design [Leaman, 2007: p.23]. They argue that practitioners of building performance evaluations need to emphasize, through clear communication, the user feedback from the building; thus strengthening the ties between stakeholders [Leaman, 2007: p.28]. In addition to their work, Baird et al. [1996] reviewed hundreds of methods for building evaluations to understand what the best methods were to improve the industry. ${ }^{1}$ However, none of this mentions the importance of communication between the stakeholders and inclusion of the occupants in a feedback loop like Leaman, Stevenson and Bordass (Leaman, et. al. 2010).

Leaman explains the concepts behind successful green buildings as having an explicit design brief in order to set targets. These are integrated into a check-list for the multidisciplinary design team, who then approach design, mindful of user's needs. This type of building would reduce energy, water usage, GHG pollution and wastage. The fabric and equipment is site sensitive and environmentally mindful. Following this, is more responsive building management during commissioning and operation with an integrated monitoring and performance system in place, POM where POE can be extended to a monitoring tool - Post Occupancy Monitoring.

In addition, a suitable extension to the local building rating system should take place, where the weightings during the design, construction and post occupancy solidify the need to perform better and create improved user satisfaction. If this can lead to willingness to share findings, the industry at large will learn from its earlier mistakes.

Buildings can be designed to fulfill these categories but may not have a strategy to maintain design standards post-construction. This is understandable, for building technologies are becoming more complicated and intelligent, it leaves a very small skilled group of people with the capability to manage them. Despite the best intentions for green buildings, the inherent problems lie in configuring their effect on occupants [Deuble, 2010: p.24]. What happens when people are left in control of the thermostat? [Lane, 2010] Unfortunately, engineers extrapolating assimilations and real results are far removed from the process of learning from buildings.

\footnotetext{
1 See also Cooper (2001) and Jaunzens et al (2002)
} 
There is a realization that a gap exists between the stakeholders, and an opportunity lies with the end-users. The data collected from users can inform future buildings (and reduce energy demand) [Zeiler et al. 2008; Deuble, 2010]. Thus, improvement of end-user evolutionary measures will indirectly improve our understanding of energy consumption, reducing it and bringing positive solutions to the environment. Similarly, users, by giving information, can ultimately improve control features within their indoor environments and thus contribute to the aim of reducing their Carbon Footprint through reduced fossil fuel electricity.

In sum, there is appreciable information regarding the design of low-energy for the environment, but not enough research regarding the implementation of the design [Short et al. 2009: p.1; Cole et al. 2003]. This is primarily because architects and engineers do not share information of building evaluations [Short et al. 2009: p.2; Bordass et al, 2001] afraid that it will reflect badly on the construction industry and user-knowledge of the product (building) is not utilized in the manner in which it could be.

The following is an introduction to POM and its methods (domestic and non-domestic) how it differs from POE, the process (PROBE), stakeholders and the necessity for policy makers to create space for rating systems that can allow for building monitoring.

\section{The Process of POM}

POM is an integrated process of building evaluation, which aims to assess the building after it has been occupied in a continuous manner. It allows the potential in reducing consumption from the inbuilt technology and improves occupant satisfaction whilst taking recurring diagnostic measures. The process of building assessment has been the centre of discussion for many years, due to its link to Green House Gases (GHG) and climate change.

POM is used for the first time in this paper as it draws from traditional POE assessment. POM differs from POE in that instead of one assessment, it allows the Facilities Management to carry out a recurring assessment on the building. The POE is one evaluation any time - 6 months after move-in. The POM, provides enough analysis continuously to assess how the building may evolve to suit both its occupants and the aims of the facilities management (FM).

POE comes from a traditional set of parameters and has developed rapidly since the 1990s (due to PROBE studies and their impact on the construction industry: see Usable Building Trust). Building performance evaluation was an "informal" process where the lessons learned were applied through personal experience [Preiser, 1995: p.20] without any formal framework to raise standards on an industry level. Since POE was introduced it has become the single methodology for evaluating buildings. It is a process which combines all elements of the building through detailed design, construction, hand over, as well as integrating a system to identify areas of weakness [Preiser et al. 1998; Preiser, 2005; Pegg, 2005: p.215; Preiser et al. 2005: p.8]. It should look at buildings in use [Leaman, 2010: p.571; Tanyer et al. 2005] for the sole purpose of understanding how it operates alone. Once the building is made, referring back to the original design intent to compare how final product compares to the design intent allows the researcher to see where the discrepancies lie. This aids future design 
strategies [Meir, 2009], preparing a list of evaluations in building design. At present, data of residential buildings is inadequate for consideration, as individual permission is needed for monitoring private spaces. Meir [2009] explains in detail that the process of POE should be a short, medium and long-term approach (see fig.1), giving benefits to the various stakeholders with contrasting degrees of information.

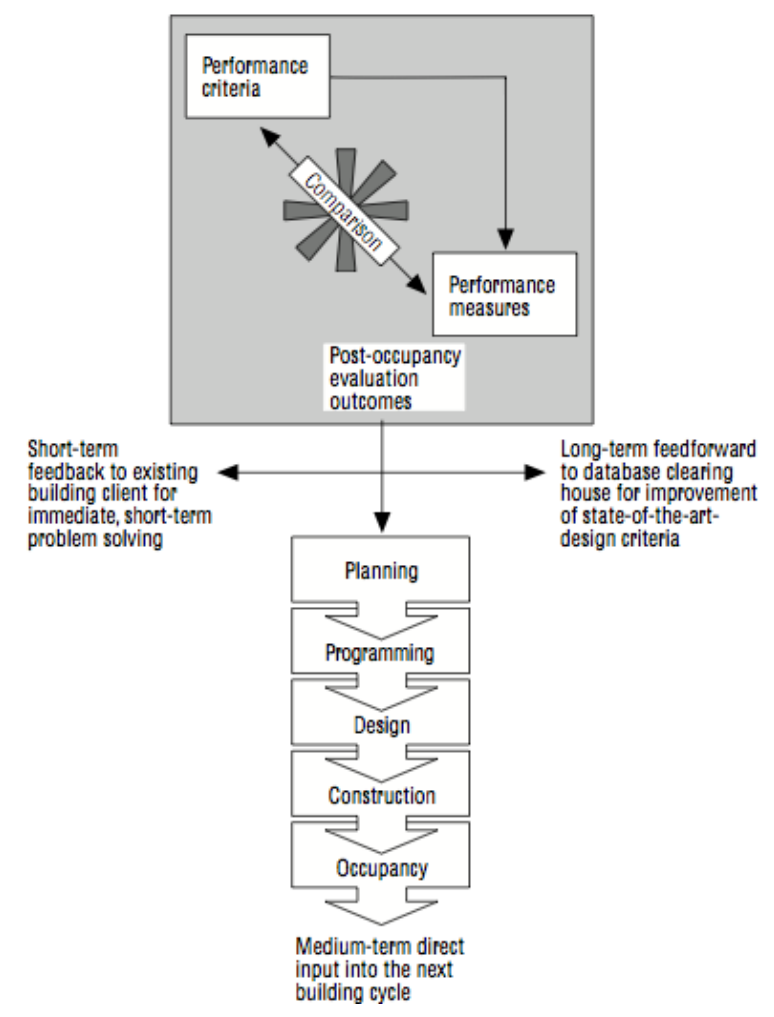

Figure 1. The Process of POE, Preiser (1995)

Just as a car that deteriorates when maintenance is ignored, other parts of the car are weighed down by core functions dwindling, further reducing the efficiency and beginning a slow deterioration. Similarly, a lack of management (of maintenance) may cause dysfunctional elements to lead to chronic malfunction [Leaman, 2010: p.572]. In fact, if these are poorly executed at the building handover and commissioning stage, these performance inefficiencies will decline when occupants move in, embedding themselves like diseases into the building. The result is poor comfort and energy efficiency.

Current practice of using Building Energy Management Systems (BEMS), an evolution from its predecessor Building Management Systems (BMS), enables the FM to collate, analyse and trend energy consumption. POM suggests the use of BEMS to facilitate the reduction of waste energy, benchmark the consumption and notify the savings.

\section{The Phases}

Adapted from Preiser [1995: p.22] this process relates to Meir's views on short, medium and long-term evaluations of POE. Preiser describes the POE methods as indicative, investigative and diagnostic: 


\section{Macrothink}

Environmental Management and Sustainable Development

ISSN 2164-7682

2013, Vol. 2, No. 2

(1) Indicative POEs are quick, walk-through evaluations, involving structured interviews with key personnel, group meetings with end-users, as well as inspections in which both positive and negative aspects of building performance are documented photographically, or on the notepad.

(2) Investigative POEs are more in-depth and they utilize interviews and survey questionnaires, in addition to photographic/ video recordings, and physical measurements. They typically involve a number of buildings of the same type.

(3) Diagnostic POEs are focused, longitudinal and cross-sectional evaluation studies of such performance aspects as stair safety, orientation and way finding, artificial versus full spectrum lighting, privacy, overcrowding, etc.

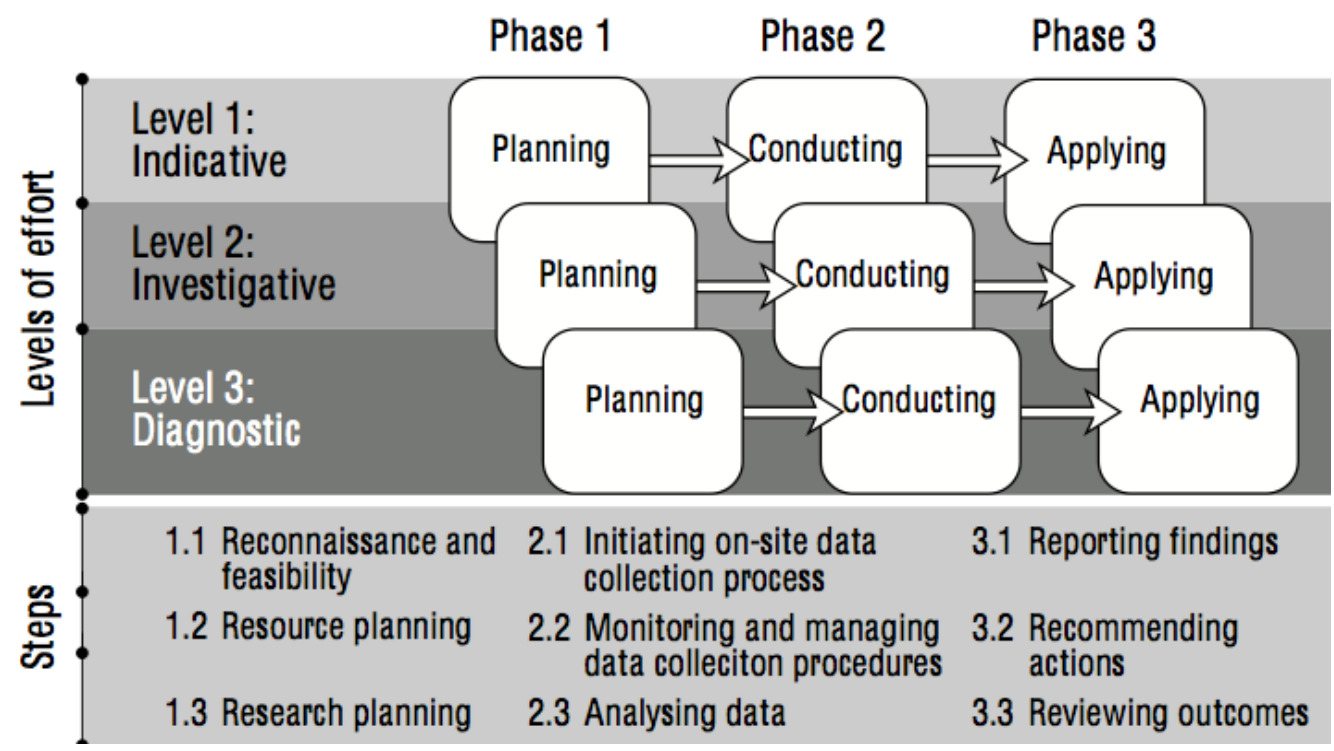

Figure 2. The various phases of POE, Preiser (1995)

\section{POE Stakeholders}

Often POE assessors are seen with suspicion and this may lead to an inability to see the benefit of learning and evaluating technologies [Meir, 2009]. In the UK a growing number of supporters are gaining recognition for POE [Pegg, 2007]. The measurement of the building in-use is necessary on three levels [Stevenson, 2010]: that of the designers, maintenance and user. A lack of sharing information between the three levels can lead to disparities and misinterpretation. No one person oversees POE project management yet [Preiser, 1995: p.21], which is the reason it is a lengthy process in getting buy-in from the various stakeholders. ${ }^{2}$ The area of POE practitioner training is under-developed, but this may not be necessary if it leads to a more participatory monitoring approach by the users themselves.

To understand the individual benefits for the various stakeholders, here is an outline of their individual requirements [adapted from Meir, 2009] and benefits from POE. Having invested the money to build, the POE offers them value for their investment. Knowing where the

\footnotetext{
2 The Soft Landing team member on site could change this, allowing for a person to be present for the duration of the handover.
} 
money invested has been used inefficiently will educate the client to evaluate future design features, based on what does and does not work. Their education is paramount to reduce further investment into poor construction. Once designs come into fruition (according to the client's wishes), bearing in mind the legislative restrictions, the architect and engineers will see how the materialization of their design is in reality. With evaluations from the facilities manager and the user, they can improve procedures for future design. This information gives them the power to understand and evaluate the contractor specifically and can shed light on what corners have been cut in the construction stages.

\subsection{Contractor $^{3}$}

Overall the building rests with the contractor to follow aspirations and ensure credibility in their product. Understanding what actions affected the performance of the building (once built) can open areas of improvements and efficiency measures to follow in future building construction.

\subsection{Facilities Manager (FM)}

Once the occupants' move in, the operation and maintenance of the building rests with the FM. It is his position that tweaks and adjusts the energy consumption; documents changes and maintenance of costs. Knowing how the building should work and documenting how the building performs through the lens of the occupant is where the biggest transformation in future buildings can occur once this information is shared between the rest of the stakeholders. The FM approaches the building in a diagnostic manner [Preiser, 1995: p.19], documenting what can be done and how to learn from the building in use. These are positive/negative lessons learned to pass to the next building cycle [Meir, 2009] including solutions to problems, if found.

\subsection{Occupant}

On a personal level, the occupant will investigate and monitor the building [Leaman, et al. 2010] and assess its user-friendliness; performance; control features and then react with levels of productivity, wellbeing and health. Knowing this information, used to effectively and speedily improve the building in maintenance, can lead to a heightened level of satisfaction for the user. A recommended method is to have a guidebook. POE can identify how much of the performance gap between the technology and the occupant's energy-use behaviour is due to the lack of education of the building features [Hydes et al. 2004; Cole et al. 2008; Stevenson et al. 2010: p.441].

Management should assess the consumption patterns of a sample of residents informed by the guidebook and those without [Stevenson, 2010]. Energy efficiency is a new way of life [Meir, 2009]. If tenants are doubtful or confused by the inbuilt features of their homes, this can only reflect negatively on the overall energy usage [Meir et al. 2007]. Must environmental constraints come at the expense of occupant thermal comfort and satisfaction? [Meir, 2008; Meir et al. 2009: p.190]

\footnotetext{
${ }^{3}$ Excluded in Meir's analysis and applies heavily in regions such as the Middle East
} 
Zeiler and Boxem [2008] wonder whether health and wellbeing are linked to thermal comfort. They point out that occupants are not empowered to understand the negative factors of their buildings. Alternatively, if buildings are energy efficient and low-carbon low waste, does the occupant need to forgo comfort to remain energy-efficient?

\subsection{Policy Makers ${ }^{4}$}

Future construction and urban planning is governed by policy makers who should understand two things from POE [Stevenson, 2010: p.3]:

1. How buildings perform according to the needs of the user; what designs and technologies work.

2. What are the areas of poor performance and what are the solutions for the wider housing industry.

The integrated approach of the POE can inform future policies to reduce energy consumption on various levels; increase user-satisfaction; reduce health and productivity issues; increase efficient and effective use of resources on a building life cycle analysis. By making POE a mandatory approach policy makers can handle large datasets by recording information (of different house types) on protocol and paradigms [Preiser, 2005]. This information can result in a realistic benchmark and statistics for future use [Bordass et al. 2005: p.351] as well as inform future smart grids and smart cities.

Pilot projects to anticipate operational design issues [Stevenson, 2009] can highlight contents for occupant guidebooks. It also offers a life-like assessment (although time restrictions apply) of occupant live-in reality.

\section{POE Methods for Domestic and Non-domestic}

The advantage of collecting information regarding non-domestic buildings [Leaman et al. 2010] is that it also gives overall consumption patterns, which can be divided between the total number of users of the buildings. This method of assessment is limited, however, and the assessor is restrained from producing a true representation of personal consumption. The method requires a cumbersome amount of assessment of exact figures of occupants in the buildings at any one time with their use of exact features, like space. POE information on hospitals [DHFP, 1990; QHRS, 2001; Carthey, 2006; Ornstein et al., 2007, Watson, 2005; Mumovic et al., 2009; Pegg et al. 2007: p.215].

A study on schools by Dejan Mumovic, Ian Ridley, Hector Altamirano-Medina and Tadj Oreszczyn [Mumovic et al. 2009] showed that indoor air quality contributed to pupils' learning performance [ibid, p.143]. An assessment of four schools showed positive results for the impact of buildings on pupils' concentration.

Domestic buildings are showing an increasing trend towards the consumption of energy [DfES, 2004] and appliance use [DfES, 2003b] with over heating and ventilation [DfES, 2003a; Pegg et al. 2007: p.215]. This is counter-balanced with knowing the personal

\footnotetext{
4 Also excluded in Meir's assessment
} 
consumption of an exact measurement of space-use in domestic buildings. An assessment of the difference between projected and actual energy use [Allwood, 2010] and its relation to the occupant behaviour (during a one-year monitoring project) found $82 \%$ higher consumption of energy consumption. Figures reaching $600 \%$ variance in the use of energy consumption [Bahaj, et al. 2007; Deuble, 2010] was a shocking realization for houses that were low-energy.

A potential reason for this is that consumer behaviour is neglected from the technical calculations of the appliances used [Hass et al. 1997]. For this reason a 'worst case scenario' should be considered. This would allow the user to understand how low-energy appliances should be used to maximize on their energy saving features. The Household Energy End-Use Project (HEEP) aims to match energy use with achieved temperatures [Isaacs et al. 2010: p.479]. This data is correlated with the use of household income data and energy expenditure to explore heating behaviour. In the UK, using one degree less of heating accounts for a $10 \%$ reduction in the annual heating bill [Directgov, 2010]. A building is a perfect setting for realizing the behaviour and human activity of the occupant [Leaman, 2010]. The relationship with the building through personal consumption is in itself a very interesting study, from how we feel in buildings to how we use them and understand them.

A variety of tools are used to undertake a POE assessment. These may include chemo-physical (air quality assessments and thermal performance) [Meir, 2009] or psychophysical where the method discusses the user satisfaction and other interactional practices. These methods fall into qualitative and quantitative methods. For occupant analysis, domestic occupants differ from non-domestic occupants. Take for example the case of office buildings, staff affected by bad office buildings and maintenance [Jaunzens, et al. 2001]:

1. Reduced comfort by noise in the open plan, bad furnishings that reflect negatively on ergonomic readings.

2. Lack of motivation; poor access to provisions of local tea/coffee/water long waiting time for facility maintenance.

3. Design features which do not include spaces for team meetings and break-out spaces to interact.

4. Wrong timings/settings for air conditioning and heating [ibid, 2002].

5. Ventilation, which does not condition spaces, instead blowing in one direction, inconveniently on staff, causing anxiety, distress and discomfort.

\section{PROBE}

Widely completed in Europe, the PROBE stages, outlined below (Fig. $3 \& 4$ ), displayed buildings with occupant measurements were not possible because sub-metering in study buildings hamper the collection of data, this meant that the adage "what you can't measure you cannot manage" has strong significance. All study buildings had some relatively advanced technology usage, and surprisingly all experienced problems. The results show the problems lie on both the controls not being set properly and lack of occupant understanding, 
therefore, misuse of the features. A solution spread across the PROBE studies would be to deliver a jargon free user-guide.

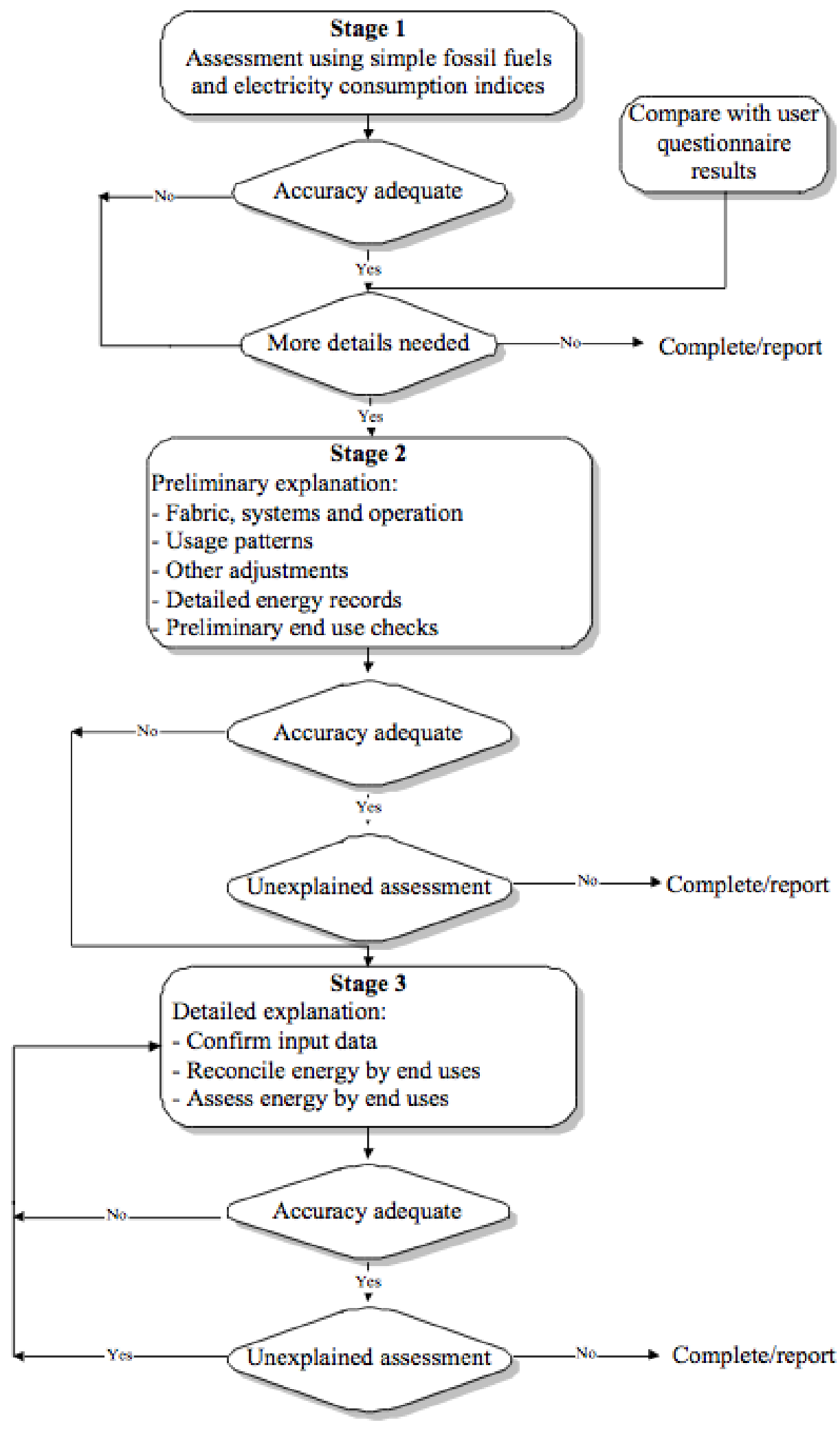

Figure 3. Stages of PROBE, Leaman et al. (1999) 


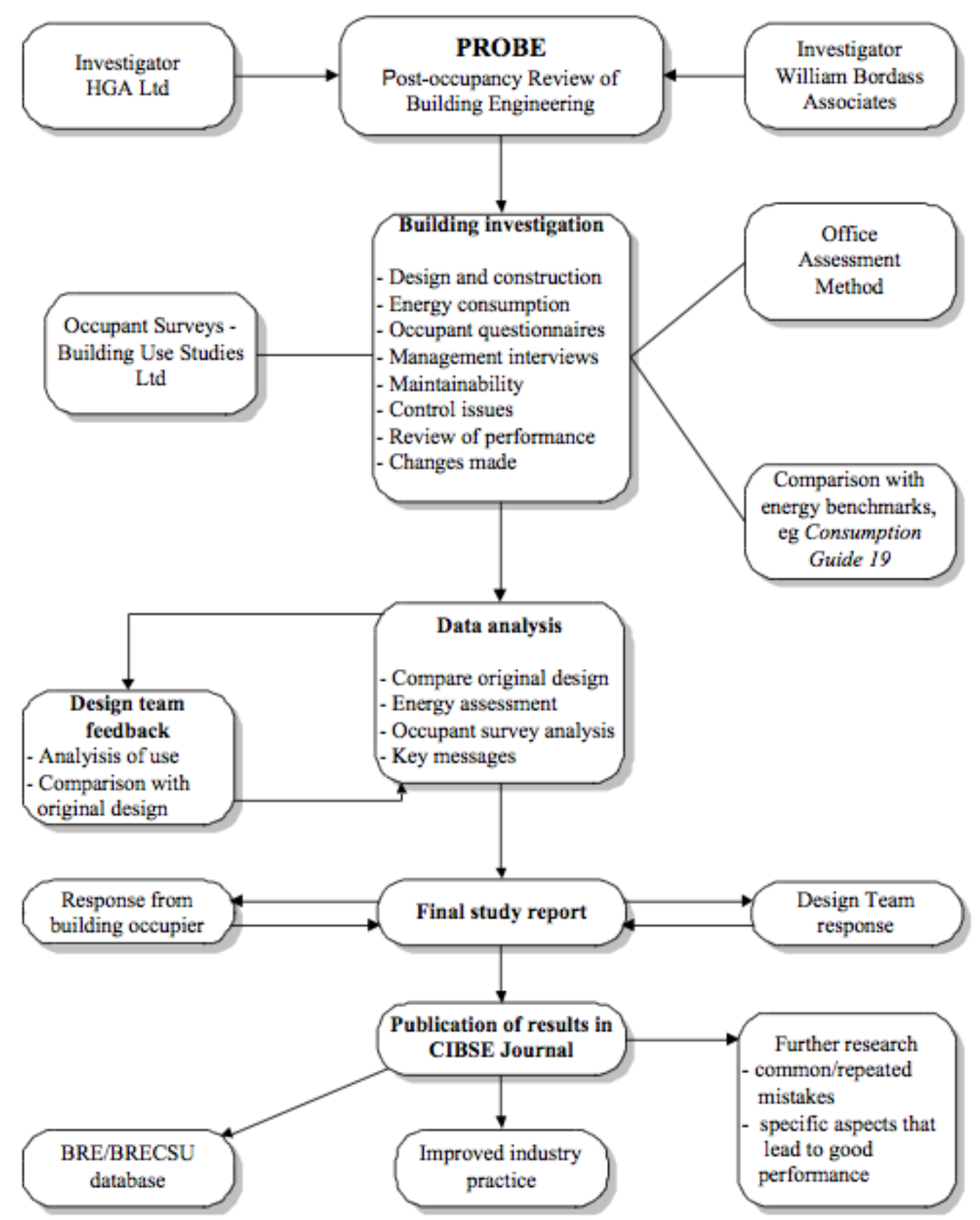

Figure 4. The PROBE Process in detail, Leaman et al. (1999)

Stevenson and Leaman argue that efficient methods of feedback are necessary if consumption reduction is to be achieved [Stevenson et al. 2010: 438]. Van Dam et al. and Darby, who suggest more informative measures such as user-interface, mirror their view; narratives and support should be more readily available for users to share in the process of reducing their own consumption.

Feedback should be objective [Leaman, 2010: p.570] and lead the audience to insights about their working practices with possible actions for solutions. Reviews should improve the performance of the buildings studied and their services [ibid, p.570]. Till [2009] and Steward 
Brand [1994] both mention the maturity of the building industry that can learn from their evaluations.

Suggestions by Stevenson and Leaman on the need for feedback to approach "interactive adaptivity" are pertinent whilst offering incentives to users for reducing their energy load [Stevenson et al. 2010: p.440]. Results from monitoring resident habits has led Stevenson to conclude that asking questions related to liveability, flexibility, space standards and maintenance reap effective strategies to investigate further the health of occupants in buildings [Stevenson, 2009]. Further to this, Gupta et al. [2010: p. 535] expand on low-carbon techniques for domestic occupants aim to challenge feedback techniques in four key parameters:

1. Perception of comfort: according to temperature; daylight; noise; and heating systems and control.

2. Satisfaction: specifically with space and flexibility; the best and worst aspects of the house such as good ventilation.

3. Behaviour: controls of heating; appliances and equipment

4. Expectation: Refurbishment for any key concerns.

Gupta and Chandiwala's feedback techniques do not cover specifics on energy consumption behaviour and how occupant behaviour challenges the use of energy or water. This is an underdeveloped area, which may find solutions from the rise in New Media strategies to deploy the right level of participation from users real-time.

\section{Evaluations of POE}

Once evaluated by POE, buildings have shown higher energy consumption and high rates of occupant dissatisfaction [Bordass, 2001; Pegg, 2005: p.215]. Therefore the barriers to a POE are [Jaunzens et al. 2002]:

- Clients who believe they spend enough time and money procuring a building and are therefore unwilling to pay more when it is meant to be finished. Clients who believe that the design team and its future clients will reap most of the benefits of a POE anyway, while a bad result might even reduce the value of their building.

- The project team who believe that they cannot afford to carry out a POE themselves and need permission from the client and the occupier in any case. If they do unearth a problem, they could attract responsibility for sorting it out and they might even be sued. They believe that their PI insurance premium could rise to cover the increased risk; and their insurance could even be invalidated [Pegg, 2007].

- Occupiers who believe that moving in is disruptive enough and they now want to get on with their life. They are not convinced of POE's cost-effectiveness. It may also get them into trouble with other players, particularly if they have already been complaining about something. 


\section{Mll Macrothink}

New Media can play a role in POM to decrease the speed at which building evaluations are used to improve future designs. Through Social Media like Facebook, Twitter, Foursquare, Instagram and websites to show real-time assessments of buildings, the public gain the power to impact the built environment. An interesting avenue to explore would be the use of new media and smart phone technology in the collection and dissemination of data from POE studies. For example applications on smart phones could be used to record occupant comfort and satisfaction votes, automating and simplifying the process of data collection. Maintenance logs or building user complaints could be posted to a website which would be accessible to current building users and potential occupants and tenants providing an incentive for appropriate action to be taken to resolve poor performance. The process of POE relies upon communication and feedback between stakeholders and could be an area which would benefit from the use of social media techniques and tools.

\section{Conclusions}

POM is a method to close the gap in construction projects and improve user satisfaction with buildings. The application of building evaluation is not popular due to competitive forces amongst the consultants (designers: architects and engineers). Afraid of bad publicity, the design consultants seldom publish information about their buildings' performances. It is difficult to determine who should pay the cost of analysis when the true recipients of the improvements are all the stakeholders. Therefore, POM hinges on government and building maintenance professionals to evaluate the building as key stakeholders (apart from the occupants who can give detailed analysis of their thermal comfort and satisfaction in the building). Designers seldom have a stake in a building once it is handed over.

User behaviour in buildings is an area hardly investigated. How buildings impact performance of students is gaining recognition, but methods to assess productivity in buildings is still debated. How bad buildings can impact the wellbeing and health of occupants is a grave concern, just as much as the general reduction of energy consumption to improve results. Much research is available on the how to reduce energy consumption but little is available on the behaviour of the occupant.

The urgency in finding a method of New Media to assess buildings via occupant experiences and characterize problems with efficient solutions through the user, are in need of further investigation. A bad building can damage health. A well performing building in use, can enhance self-esteem, and raise the spirit.

\section{References}

Alcorn, J. A., Baird, G. (1996). Use of a hybrid energy analysis method for evaluating the embodied energy of building materials. Renewable energy, 8 (1-4) 319-322. http://dx.doi.org/10.1016/0960-1481(96)88869-0

Bahaj, A.S., James, P.A.B., (2007). Urban energy generation: the added value of photovoltaics in social housing. Renewable and Sustainable Energy Reviews 11, 2121-2136. http://dx.doi.org/10.1016/j.rser.2006.03.007 
Bordass W., Cohen R., Standeven M., \& Leaman A. (2001). Assessing building performance in use 3: energy performance of the Probe buildings. Building Research \& Information, 29, (2)

Brand, S. (1995). How building learn: what happens after they're built. Penguin Books

Burge, S., Hedge, A., Wilson, S., Bass, J. H., Robertson, A. (1987). Sick Building Syndrome: A study of 4373 office workers. British Occupational Hygiene Society, 31 (4A) 493-504. http://dx.doi.org/10.1093/annhyg/31.4A.493

Carthey, J. (2006). Post occupancy evaluation: development of a standardized methodology for Australian health projects. The International Journal of Construction Management pp. 57 $-74$.

CIBSE (1999). Energy Codes part 1 and 2. CIBSE

Cole, R. J. (2003). Green Buildings - Reconciling Technological Change and Occupant Expectations Chapter 5. In Cole, R. J., \& Lorch, R. (Eds) Buildings, Culture and Environment. Blackwell, Oxford

Cole, R. J. (2008). Building environmental assessment methods: A review of international developments. Report submitted to World Green Building Council

Cullen, J. M., \& Allwood, M. (2010). The efficient use of energy: Tracing the global flow of energy from fuel to service. Energy Policy 38: 75-81. http://dx.doi.org/10.1016/j.enpol.2009.08.054

Deuble, R. (2010). Green Occupants for Green Buildings: The Missing Link. Adapting to Change: New Thinking on Comfort. Windsor

DfES (2003a). Building Bulletin 87 - guidelines for environmental design in schools. Department for Education and Skills, The Stationary Office

DfES (2003b). Building Bulletin 93 - Acoustic design of schools. Department for Education and Skills, The Stationary Office

DHFP (1990). Indian Health Service Hospital Browning Montana Facility Post Occupancy Evaluation. Division of Health Facilities Planning, Office of Resource Management, Office of Management

Directgov (2010). Top Tips on Saving Energy, Directgov, London. [Online] Available: http://www.direct.gov.uk/en/Environmentandgreenerliving/Energyandwatersaving/Energyan dwaterefficie ncyinyourhome/DG_064371) [April 9th 2010]

Dunlap, R. E. (2008). The New Environmental Paradigm Scale: From Marginality to Worldwide Use. Journal of Environmental Education, 40 (1) 3-18. http://dx.doi.org/10.3200/JOEE.40.1.3-18

Fisk, W. J. (2000). Health and productivity gains from better indoor environments and their relationship with building energy efficiency. Annual Review of Energy and the Environment, 
25, 537-566. http://dx.doi.org/10.1146/annurev.energy.25.1.537

Hass, H., Builtjes, P. J. H., Simpson, D., Sternil, R. (1997). Comparison of model results obtained with several European regional air quality models. Atmospheric Environment, 31 (19)3259-3279. http://dx.doi.org/10.1016/S1352-2310(97)00066-6

Hydes, K. P., McCarry, B., Mueller, T., \& Hyde, R. (2004). Understanding our green buildings: Seven post-occupancy evaluations in British Columbia, in Proceedings of SBSE Conference Closing The Loop: Post Occupancy Evaluation: The Next Steps. Windsor, UK, Society of Building Science Educators, 29 April-2 May, CD-Rom IAUA (Israel Association of United Architects) (1994) Bylaws of Engineers and Architects, IAUA. [Online] Available: www.isra-arch.org.il/ (February $1^{\text {st }}$ 2011)

Isaacs, N.P. (Ed.). Camilleri, M., French, L., Pollard, A., Saville- Smith, K., Fraser, R., Rossouw, P., \& Jowett, J. (2010) Energy Use in New Zealand Households: Final Report on the Household Energy End-use Project (HEEP). Study Report No. 221, BRANZ, Judgeford

Kats, G. H. (2003). The costs and financial benefits of green buildings. Massachusetts Technology Collaborative

Lane, T. (2010). The Big Brother Houses: Monitoring Residents' Energy Use. [Online] Available: http://www.building.co.uk/the-big-brother-houses-monitoring-residents-energy-use/3163348. article [December 20th 2010]

Leaman, A.; Stevenson, F.; Bordass, B. (2010). Building evaluation: practice and principles. Building research and information, 38 (5) 564-577. http://dx.doi.org/10.1080/09613218.2010.495217

Leaman, A., Thomas, L., \& Vandenberg, M. (2007). Green buildings: what Australian building users are saying. EcoLibrium

Meir, I., Garb, Y., Jiao, D., \& Cicelsky, A. (2009). Post-Occupancy Evaluation: An Inevitable Step Toward Sustainability. Advances in building energy research, 189-220. http://dx.doi.org/10.3763/aber.2009.0307

Mumovic, D., Davies, M., Ridley, I., Altamirano-Medina, H., Oreszczyn, T. (2009). A Methodology for Post-Occupancy Evaluation of Ventilation Rates in Schools. Building Services Engineering Research and Technology, 30 (2) 143-52

Ornstein, S. W., Ono, R., Lopes, M. E., Monteiro, R.Z., Gill, A. A., Machry, H.S. (2007). Health Care Architecture in São Paulo, Brazil Evaluating Accessibility and Fire Safety in Large Hospitals. International Journal of Architectural Research, 1 (1) 13-25

Pegg, I., Cripps, A., \& Kolokotroni, M. (2005). A Post-Occupancy Evaluation of a Low Energy School (City Academy). The UK. International Journal of Ventilation ISSN 1473-3315 Volume 4 No 3

Pegg I., Cripps A., \& Kolokotroni M. (2007). Post-occupancy Energy Performance: The Development of a Local Urban Climate Model and its Application. Wind driven natural 
ventilation and cooling for non-domestic buildings

Preiser, W.F.E., Robinowitz,H.Z. \& White, E.T. (1988). Post-Occupancy Evaluation. Van Nostrand Reinhold, New York

Preiser, W. F. E. (1995). Post-occupancy evaluation: how to make buildings work better. Facilities Journal, 13 (11) 19-28. MCB University Press

QHRS (2001). Royal Children's Hospital Post Occupancy Evaluation, Queensland Health and Royal Children's Hospital Health Service District

Short, A., Cook, M., \& Lomas, K. (2009). Delivery and performance of a low-energy ventilation and cooling strategy. Building Research and Information, 37 (1), 1-30. http://dx.doi.org/10.1080/09613210802607841

Stevenson, F., \& Leaman, A. (2010). Evaluating housing performance in relation to human behaviour: new challenges. Building Research \& Information 38 (5), 437-441. http://dx.doi.org/10.1080/09613218.2010.497282

Till, J. (2009). Architecture depends. MIT Press, Cambridge, MA

Tanyer, A. M., \& Pembegul, T. (2005). Post occupancy evaluation in the practice of architecture: A case study of Lutfi Kirdar convention and exhibition centre. In Aouad, G, Lees, A., \& Wu, S. (2006). Constructing the future and modeling, Taylor \& Francis

Upson, C., Faulhaber, T.A., Jr.; Kamins, D.; Laidlaw, D.; Schlegel, D.; Vroom, J.; Gurwitz, R.; van Dam, A. (1989). The application visualization system: a computational environment for scientific visualization. Computer Graphics and Application, 9 (4), 30-42. http://dx.doi.org/10.1109/38.31462

Watson, C. (2005). Post Occupancy Evaluation - Braes High School, Falkirk, Scottish Executive. [Online] Available: www.scotland.gov.uk/ Publications/2006/01/23112827/11 [February $\left.2^{\text {nd }} 2011\right]$

Zeiler, W., \& Boxem, G. (2008). Sustainable schools: Better than traditional schools? In Proceedings of Indoor Air 2008 Conference, Copenhagen, Denmark, 17-22 August, Paper ID: 10 (electronic proceedings version only)

Zeiler, W., Savanovic, P., \& Boxem, G. (2008). Design decision support for the conceptual phase of sustainable building design. In B. W. Olesen et al (Eds), The 11th International Conference on Indoor Air Quality and Climate, Copenhagen, Technical University of Denmark, vol CD, pp1-8

\section{Copyright Disclaimer}

Copyright reserved by the author(s).

This article is an open-access article distributed under the terms and conditions of the Creative Commons Attribution license (http://creativecommons.org/licenses/by/3.0/). 